\title{
Auxiliary midwives in hard to reach rural areas of Myanmar: filling MCH gaps
}

Sangay Wangmo ${ }^{{ }^{*}}$ (D, Rapeepong Suphanchaimat ${ }^{1}$, Wai Mar Mar Htun², Tin Tun Aung ${ }^{2}$, Chiraporn Khitdee ${ }^{1}$, Walaiporn Patcharanarumol ${ }^{1}$, Pe Thet Htoon ${ }^{3}$ and Viroj Tangcharoensathien ${ }^{1}$

\begin{abstract}
Background: Auxiliary Midwives (AMWs) are community health volunteers supporting the work of midwives, especially maternal and child health services in hard to-reach areas in Myanmar. This paper assessed the contributions of AMW to maternal and child health services, factors influencing their productivity and their willingness to serve the community.
\end{abstract}

Method: The study applied quantitative cross-sectional survey using census method. Total of 1,185 AMWs belonging to three batches: trained prior to 2000, between 2000 and 2011, and in 2012, from 21 townships of 17 states and regions in Myanmar participated in the study. Multiple logit regression was used to examine the impact of age, marital status, education, domicile, recruitment pattern and 'batch of training', on AMW's confidence level in providing care, and their intention to serve the community more than 5 years.

Results: All AMWs were able to provide essential maternal and child health services including antenatal care, normal delivery and post-natal care. They could identify and refer high-risk pregnancies to larger health facilities for proper management. On average, 9 deliveries, 11 antenatal and 9 postnatal cases were performed by an AMW during the six months prior to this study. AMWs had a comparative advantage for longer service in hard-to-reach villages where they lived, spoke the same dialect as the locals, understood the socio-cultural dimensions, and were well accepted by the community. Despite these contributions, $90 \%$ of the respondents expressed receiving no adequate supervision, refresher training, replenishment of the AMW kits and transportation cost. AMWs in the elder age group are significantly more confident in taking care of the patients than those in the younger groups. Over $90 \%$ of the respondents intended to stay more than five years in the community. The confidence in catering services appeared to have significant association with a longer period of stay in AMW jobs as evidenced by the odds ratio of 3.5, compared to those reporting unconfident.

Conclusions: Comprehensive support system and national policy are needed to sustain and strengthen the contributions of AMWs, in sharing the workload of midwives, particularly in hard-to-reach areas of Myanmar.

Keywords: Auxiliary midwife, Frontline health volunteers, Human resource for health, Maternal and child health, Task Shifting, Health system strengthening, Myanmar

Abbreviations: AIDS, Acquired immune deficiency syndrome; AMW, Auxiliary midwife; BHS, Basic health staff; GAVI, Global alliance on vaccine and immunization; GNI, Gross national income; HIV, Human immunodeficiency virus; HRH, Human resource for health; HSS, Health system strengthening; LHW, Lay health workers;

MDG, Millennium development goal; MOH, Ministry of health; ODA, Official development assistance; RHC, Rural health centres; UNICEF, United Nations international children's emergency fund; WHO, World Health Organization

\footnotetext{
* Correspondence: sangay@ihpp.thaigov.net

${ }^{1}$ International Health Policy Program (IHPP), Ministry of Public Health,

Tiwanon Road, Nonthaburi 11000, Thailand

Full list of author information is available at the end of the article
} 


\section{Background}

The Republic of the Union of Myanmar is in the middle of vibrant political, social and economic transitions. Despite the recent positive economic performance, Myanmar is classified as lower middle income with estimated GNI per capita of $\$ 1280$ in 2015 [1]. Myanmar was still not on track in achieving MDG by 2015, especially its infant and child mortality indicators [2]. On the progressive note, health expenditure in Myanmar had increased from $1 \%$ of total government expenditure in 2005 to $3 \%$ in 2012 [3], although at a very low level, it demonstrated strong political commitment to health.

Severe shortage of human resources for health (HRH), impedes the performance of many countries in achievement of Millennium Development Goals (MDGs) 4 and $5[4,5]$. Further the challenge of deployment, retention, distribution and performance of health workforce, experienced by countries of all socio economic conditions, makes it worse [6-9]. Myanmar for one is among 57 countries experiencing critical shortage of health workforce with 1.61 doctors, nurses and midwives per 1,000 population [10]. This falls below the suggested threshold of 2.28 per 1,000 population, a level that ensures high coverage of essential health services [11]. Not only is there an inadequacy of health workforce but also the maldistribution is jeopardizing access to services, resulting in poor health status amongst people living in hardto-reach areas. Internal migration of health workers from rural to urban areas, from the public to the private sector and from primary health care level to the higherup care level and some quitting from the profession, all exacerbate the health workforce scarcity and jeopardize the achievement of health related MDG.

Public health in Myanmar faced critical resource constraints, creating major gaps in access to, and coverage of health services [12]. Myanmar's slow progress on key maternal health indicators, including skilled birth attendance, antenatal care coverage between 1990 and $2010[13,14]$, has strong linkage to human resource shortage, particularly in the hard to reach and remote areas. Country's current health workforce strategic plan recommends continued commitment from government to invest in training and to ensure rural retention of health workforce [15].

Varieties of community-based practitioners are used in escalating access to essential health services, mainly in the under-served communities of low- and middle- income countries [16-18]. Among them, auxiliary health workers are increasingly becoming the main providers of health services in many countries. For instance, despite the professional restrictions and regulations, auxiliary workers like nurse aids and clinical officers in Tanzania and Uganda provides essential medical tasks, in rural areas [19]. In many countries, auxiliary nurses and lay health workers are well accepted and recognised by the community, for their contribution in enhancing availability and accessibility of health services at lower costs, and in addressing the shortage or misdistribution of human resources for health [20].

Recognising its benefit, Myanmar also trained and deployed Auxiliary Midwives (AMWs) to perform as extension arms of limited number of trained health workforce especially midwives, in delivering $\mathrm{MCH}$ services to the hard-to-reach and remote areas. The Ministry of Health (MOH) executes the AMW training programme by mobilising funding from various sources, either from the MOH's core budget or international development partners when opportunities arose.

In addition to introducing new and under-used vaccines, the Global Alliance on Vaccine and Immunization (GAVI) had provided Myanmar with funding to support Health Systems Strengthening (HSS) programme. The GAVI HSS supported recruitment and training of new AMWs, as well as refresher courses for the existing AMWs in the townships implementing GAVI HSS. Due to resource constraints, each township had annual quota of 20 seats for new recruitment of a six-month training to be an AMW, and an annual quota of 50 seats for AMWs trained after 2012, to attend refresher course.

As a part of routine monitoring and evaluation of GAVI HSS project in Myanmar, a quantitative crosssectional study was conducted in 2013, to assess the extent of AMW's contribution in addressing the shortage of midwives, by assisting the existing midwives in delivering $\mathrm{MCH}$ services to the communities of hard to reach areas. This study aimed to understand AMW's strengths, weakness and support needed, to better inform future policy decision in strengthening the AMW program in Myanmar.

\section{Methods \\ Study design}

This study applied cross-sectional design, using quantitative self-administered questionnaire. The study was carried out in nineteen townships where the GAVI HSS program was implemented, plus two new townships (Pinlong and Thanatpin) where the GAVI HSS was about to commence by 2014 .

As the study aimed to assess all AMWs in the programme, a census was applied instead of a random sampling survey. Questionnaires were distributed to Basic Health Staff (BHS) of all health facilities in these 21 townships, at the July 2013 township monthly meeting. The BHS circulated the questionnaires to all AMWs in their catchment area after the meeting. After reading and signing the consent form on the first page of questionnaire, respondents were requested to answer the questionnaires independently; BHS then collected the 
completed questionnaires. Since it was difficult to gather all AMWs in one place, some BHS outreached their houses and collected the filled questionnaires.

\section{Pilot test and questionnaire distribution}

The first draft questionnaire was tested on the relevance of contents (content validity) to AMW in the catchment areas of two selected rural health centres in two townships, one as best and the other worst performing, in view of the township medical officer. The questionnaire was already translated to Burmese language prior to the test. A total of 33 AMWs participated in the test.

After piloting, contents of the questionnaire were reviewed, revised and finalized before submission to the selected townships. The completed questionnaires were collected from BHS during the township monthly meeting in August 2013. All questionnaires were sent to the WHO country office in Yangon by pouch.

\section{Questionnaire design}

The contents of questionnaire were divided into three parts. The first part included questions on personal attributes, such as age, marital status, education, domicile (if they were living in the village they served, or otherwise) and main job. The second part covered history of being an AMW, who proposed them for training, their main motivation, when were they newly trained or refreshed (recent GAVI batch in 2012, older batches between 2000 and 2011 and oldest batch prior to 2000), and their level of confidence to provide service to villagers (Likert -type scale from 1 to 4 , from very confident to not confident). The third part was related to their contributions to villages, including number of high risk pregnancies identified and referred, and number of refusal to referral, number of antenatal care, delivery and postnatal care they had provided in the last six months, their needs for supports, such as incentives for their work, transport, and or refresher training, their perception of being accepted by the communities, support they got from communities and patients they served, and satisfaction with supports from rural health centre (RHC) and sub-centre. This section ended up with number of years they intended to serve the communities and reasons to quit from AMW (arranged in Likert-typed scale: 1 as 'less than one year', 2 as ' $1-3$ years', 3 ' $3-5$ years', and ' $>5$ years'.

\section{Data analysis}

Data were entered in Excel and were transferred to STATA XI (STATA - 12, Stata Corporation, College Station, Texas, USA) for the analysis. The analysis was composed of two steps. Firstly, the descriptive statistics using means and frequency were applied to explore general information of the respondents' characteristics.
Secondly, inferential statistics, including multiple logit regression, were exercised.

The dependent variables for the analysis in the second step were (1) confidence level in providing care, and (2) intention to serve the community more than 5 years. These variables were converted from ordinal scale variables to binary variables. That is, respondents answering 1 (very confident) or 2 (confident) in the question on level of confidence were coded as 1 (confident) and 0 (not confident) if otherwise. Those, who reported intending to continue their stay in the community for more than 5 years (answering choice 4 in the question), were coded as 1 (intending to stay) and 0 (not intending if otherwise).

In the multiple logit regression, these dependent variables were regressed one by one on all of the following independent variables, namely, 'age group', 'education level' (grade 5, 9, 11 and bachelor or above), 'recruitment pattern' (self-application, proposed by midwives, villagers and village head), and 'batch of training' (before 2000, 2000-2011 and 2012) included in the model.

Notice is made that in the inferential analysis of intention to serve the community beyond the next 5 years, an additional independent variable, that is level of confidence (which served as the dependent variable in the previous model) was put into the model as well, since the researchers hypothesised that the confident workers were more likely to show interest in engaging in AMW job for a longer period of time than the unconfident ones.

The decision of selecting variables into the model was based on consultative meetings between the research team and external experts held in WHO Country Office Myanmar. The variables selection was derived from prior knowledge in academic literature [21] that, aside from the programme determinants, such as training batch and how they were recruited to the programme, background of the respondents (such as age and education level) is of importance in determining the confidence in providing care and intention to serve the community. P-value of 0.05 was used as a cut-off point for statistical significance.

\section{Results}

1. Profiles of AMW From the census, total 1,185 AMW from 21 townships completed the questionnaire; all were women and about half were married. The majority of respondents were in an age group of 30 years or more, and completed their education up to grade 11. This reflected that most AMW were educated at least up to essential education, though very few of them finished a degree level. 
Almost all of the respondents (98\%) lived in the village where they provided services. Being AMW was a voluntary job as all respondents already had other main occupations; about three quarters of them earned living from farming, see Table 1.

2. Becoming an auxiliary midwife: the pathways The majority of AMW (59\%) came to this work from self-application. The most important reason for joining this programme was the chance to serve the community. For reasons of becoming AMW, altruism was the main motivation to be an AMW, as $89 \%$ reported this was a chance to serve people in their own village, and $6 \%$ stated that they wished to be upgraded to a midwife. Less than half percent reported a chance to earn some money from their services. About $39 \%$ of the respondents were trained before 2000 and over half of the respondents ever attended refresher course.

After the six-month training course, over four fifths of the participants reported 'fairly confident' to 'very confident' in providing care, see Table 2.

3. AMW: contributions of and supports to AMW In the past six months prior to the survey, on average, 2.9 high-risk pregnancies were identified and referred by them to the respective Township Hospital. The participants also reported they had assisted an average of nine deliveries in the last six months, eleven antenatal care cases and nine postnatal cases. Concerning support from the sub-centre

Table 1 Profiles of auxiliary midwives $(N=1,185)$

\begin{tabular}{lll}
\hline Characteristics & Frequency & Percent \\
\hline Age & 83 & 7.1 \\
$<20$ years & 397 & 33.9 \\
20-29 years & 312 & 26.6 \\
30-39 years & 191 & 16.3 \\
40-49 years & 188 & 16.1 \\
$>=50$ years & & \\
Education & 151 & 12.8 \\
Up to grade 5 & 403 & 34.3 \\
Up to grade 9 & 554 & 47.1 \\
UP to grade 11 & 68 & 5.8 \\
Degree or above & & \\
Domicile & 1,139 & 97.6 \\
Living in the service area & 28 & 2.4 \\
Living outside the service area & & 71.1 \\
Main occupation & 800 & 17.1 \\
Farming & 192 & 11.8 \\
Shop owner & 133 & \\
Others & &
\end{tabular}

Note: Missing data are not included in the analysis
Table 2 Factors and pathway to become auxiliary midwives

\begin{tabular}{|c|c|c|}
\hline Variables & Frequency & Percent \\
\hline \multicolumn{3}{|l|}{ Proposing person } \\
\hline Village head & 172 & 15.0 \\
\hline Villagers & 76 & 6.6 \\
\hline Midwives & 228 & 19.9 \\
\hline Self applying & 671 & 58.5 \\
\hline \multicolumn{3}{|l|}{ Reasons for application } \\
\hline Having chance to serve villagers & 1,002 & 88.5 \\
\hline Being recognised by community & 64 & 5.6 \\
\hline Having chance to be upgraded to midwife & 63 & 5.6 \\
\hline Earning more revenue & 3 & 0.3 \\
\hline \multicolumn{3}{|l|}{ Batch } \\
\hline Year 2012 & 308 & 26.7 \\
\hline Year 2000-2011 & 396 & 34.4 \\
\hline Before 2000 & 449 & 38.9 \\
\hline \multicolumn{3}{|l|}{ Attending refresher course (in 2012) } \\
\hline Ever attended & 513 & 58.2 \\
\hline Not attended & 368 & 41.8 \\
\hline \multicolumn{3}{|l|}{ Confidence after attending refresher course } \\
\hline Very confident & 289 & 25.0 \\
\hline Confident & 693 & 60.1 \\
\hline Fairly confident & 162 & 14.0 \\
\hline Not confident & 7 & 0.6 \\
\hline Not confident at all & 3 & 0.3 \\
\hline
\end{tabular}

or RHC, only $3 \%$ of respondents answered 'not satisfied' to the support received. The survey found that $72 \%$ of them reported they were well accepted by their community, and only infinitesimal group of respondents reported not being accepted by the villagers.

Approximately two thirds of the respondents reported difficulty in travelling to households of women and children in need in remote or hard-toreach areas. Concerning sources of financial assistance, about $9 \%$ of the respondents received financial support from the community and $39 \%$ got payments from the patients they served.

The majority of respondents opined that they still needed support in the following items for improving their quality of care, such as technical supervision (99\%), refresher course (99\%), replenishment of AMW kits (96\%), and transportation to reach hardto-reach villagers $(74 \%)$, see Table 3.

4. AMW: Intention to stay

A futuristic question was asked on how many years they intended to serve as AMW. The majority, $90 \%$, reported an intention to serve the community more than 5 years, whilst only $1 \%$ expected to be engaged 
Table 3 Contribution of AMW and their needed support

\begin{tabular}{|c|c|c|}
\hline Contributions of AMW & Mean & $\begin{array}{l}\text { Standard } \\
\text { error }\end{array}$ \\
\hline Number of referred pregnant cases & 2.9 & 5.2 \\
\hline Number of deliveries & 9.0 & 29.2 \\
\hline Number of cases received antenatal care & 11.5 & 29.9 \\
\hline $\begin{array}{l}\text { Number of deliveries in the last six } \\
\text { month }\end{array}$ & 9.2 & 34.4 \\
\hline Support to AMW & Frequency & Percent \\
\hline \multicolumn{3}{|l|}{ Support from rural health centre } \\
\hline Very satisfied & 325 & 28.0 \\
\hline Satisfied & 674 & 58.1 \\
\hline Fairly satisfied & 112 & 9.7 \\
\hline Unsatisfied & 38 & 3.3 \\
\hline Very unsatisfied & 10 & 0.9 \\
\hline \multicolumn{3}{|l|}{ Travelling difficulty to hard to reach areas } \\
\hline Having difficulty & 692 & 65.5 \\
\hline Not having difficulty & 395 & 34.5 \\
\hline \multicolumn{3}{|l|}{ Experiencing patients refusing to be referred to } \\
\hline \multicolumn{3}{|l|}{ higher facilities } \\
\hline Ever experienced & 546 & 57.2 \\
\hline Never experienced & 408 & 42.8 \\
\hline \multicolumn{3}{|l|}{ Sources of financial assistance } \\
\hline \multicolumn{3}{|l|}{ From community fund } \\
\hline Ever received & 89 & 8.7 \\
\hline Never received & 932 & 91.3 \\
\hline \multicolumn{3}{|l|}{ From individual patients } \\
\hline Ever received & 414 & 39.0 \\
\hline Never received & 649 & 61.0 \\
\hline \multicolumn{3}{|l|}{ Needed support } \\
\hline \multicolumn{3}{|l|}{ Technical supervision } \\
\hline Needed & 1100 & 99.1 \\
\hline Not needed & 10 & 0.9 \\
\hline \multicolumn{3}{|l|}{ Refresher course } \\
\hline Needed & 1054 & 99.0 \\
\hline Not needed & 11 & 1.0 \\
\hline \multicolumn{3}{|l|}{ Kits replenishment } \\
\hline Needed & 949 & 96.0 \\
\hline Not needed & 40 & 4.0 \\
\hline \multicolumn{3}{|l|}{ Transportation support } \\
\hline Needed & 691 & 74.0 \\
\hline Not needed & 243 & 26.0 \\
\hline
\end{tabular}

in this work for less than a year. The main reasons of quitting were; if they needed to change their domicile (21\%) and if they were not able to contribute to the community as intended (23\%), see Table 4.
Table 4 Expected years to serve the community and potential reasons for quitting AMW job

\begin{tabular}{|c|c|c|}
\hline Variables & Frequency & Percent \\
\hline \multicolumn{3}{|l|}{ Expected years to serve the community } \\
\hline$<1$ years & 12 & 1.1 \\
\hline $1-3$ years & 58 & 5.1 \\
\hline $3-5$ years & 39 & 3.5 \\
\hline$>5$ years & 1019 & 90.3 \\
\hline \multicolumn{3}{|l|}{ Reasons for quitting AMW jobs } \\
\hline \multicolumn{3}{|l|}{ Marriage } \\
\hline May consider quitting jobs & 45 & 4.2 \\
\hline Not relevant to the decision of quitting jobs & 1023 & 95.8 \\
\hline \multicolumn{3}{|l|}{ Changing domicile } \\
\hline May consider quitting jobs & 218 & 21.3 \\
\hline Not relevant to the decision of quitting jobs & 806 & 78.7 \\
\hline \multicolumn{3}{|l|}{ Having another permanent job } \\
\hline May consider quitting jobs & 124 & 12.4 \\
\hline Not relevant to the decision of quitting jobs & 878 & 87.6 \\
\hline \multicolumn{3}{|c|}{ Cannot contribute to the community as much as expected } \\
\hline May consider quitting jobs & 228 & 22.6 \\
\hline Not relevant to the decision of quitting jobs & 779 & 77.4 \\
\hline
\end{tabular}

5 AMW: confidence and intention to contribute more than five years Multiple logit regression reveals that the older AMW were, the more confident in providing service. Those aged 50 or more tended to be approximately 5 folds more confident than the youngest age group with statistical significance. Conversely, AMW who completed up to grade five, those who self-applied, and were trained before 2000 , were likely to report having confidence in service provision despite without statistical significance, see Table 5 .

Results from multiple logit regression, where intention to contribute more than 5 years serving as the dependent variable is demonstrated in Table 6. It is clear that the confident respondents showed higher probability to stay longer than 5 years as presented by the odds ratio of 3.5 with statistical significance. Also the older the respondents were, the higher was the probability of intending to stay more than five years but without statistical significance.

The respondents with an education background more than grade 5 were likely to engage in AMW work for a shorter period of time than those completing up to grade 5 . Those recruited to the training programme through other means tended to contribute to this work shorter than the self-applicants. This phenomenon was observed in those trained in the 
Table 5 Multiple logit regression: factor contributing to confidence in providing services

\begin{tabular}{lcccc}
\hline Feeling confident & Odd ratio & $P$-value & $95 \% \mathrm{Cl}$ & \\
\hline Age (versus < 20 years) & & & & \\
20-29 & 1.038 & 0.899 & 0.583 & 1.850 \\
$30-39$ & 1.493 & 0.257 & 0.747 & 2.981 \\
$40-49$ & 6.019 & 0.000 & 2.259 & 16.038 \\
$>=50$ & 4.966 & 0.001 & 1.892 & 13.031 \\
Education (versus up to grade 5) & & & \\
Up to grade 9 & 0.713 & 0.347 & 0.353 & 1.443 \\
Up to grade 11 & 0.642 & 0.214 & 0.319 & 1.291 \\
Up to bachelor or above & 0.478 & 0.111 & 0.192 & 1.186 \\
Recruitment by (versus self applying) & & & \\
Local midwives & 0.944 & 0.788 & 0.623 & 1.433 \\
Villagers & 0.655 & 0.216 & 0.335 & 1.280 \\
village head & 0.866 & 0.581 & 0.520 & 1.444 \\
Training batch (versus year 2000) & & & \\
2000-2011 & 1.703 & 0.062 & 0.974 & 2.977 \\
2012 & 1.062 & 0.849 & 0.574 & 1.963 \\
\hline
\end{tabular}

later batches, particularly the participants in the 2012 batch was about $75 \%$ less likely to serve the community for more than 5 years, compared to those received training before 2000 with statistical significance.

Table 6 Multiple logit regression: factor contributing to intention to contribute more than five years

\begin{tabular}{|c|c|c|c|c|}
\hline \multirow{2}{*}{$\begin{array}{l}\text { Intention to serve communities } \\
>5 \text { years } \\
\text { Confidence in providing services } \\
\text { (VS not confident) }\end{array}$} & \multirow{2}{*}{$\begin{array}{l}\text { Odd } \\
\text { Ratio } \\
3.486\end{array}$} & \multirow{2}{*}{$\begin{array}{l}\text { Pvalue } \\
<0.001\end{array}$} & \multicolumn{2}{|c|}{$95 \% \mathrm{Cl}$} \\
\hline & & & 2.195 & 5.537 \\
\hline \multicolumn{5}{|l|}{ Age (versus < 20 years) } \\
\hline $20-29$ & 1.327 & 0.382 & 0.703 & 2.506 \\
\hline $30-39$ & 1.783 & 0.171 & 0.779 & 4.079 \\
\hline $40-49$ & 1.710 & 0.330 & 0.582 & 5.025 \\
\hline$>=50$ & 2.532 & 0.147 & 0.720 & 8.901 \\
\hline \multicolumn{5}{|l|}{ Education (versus up to grade 5) } \\
\hline Up to grade 9 & 0.345 & 0.096 & 0.099 & 1.207 \\
\hline Up to grade 11 & 0.255 & 0.031 & 0.074 & 0.881 \\
\hline Up to bachelor or above & 0.531 & 0.441 & 0.106 & 2.657 \\
\hline \multicolumn{5}{|l|}{ Recruitment by (versus self applying) } \\
\hline Local midwives & 0.726 & 0.247 & 0.422 & 1.248 \\
\hline Villagers & 0.324 & 0.004 & 0.150 & 0.701 \\
\hline village head & 0.300 & $<0.001$ & 0.168 & 0.535 \\
\hline \multicolumn{5}{|l|}{ Training batch (versus year 2000) } \\
\hline 2000-2011 & 0.655 & 0.301 & 0.294 & 1.460 \\
\hline 2012 & 0.252 & 0.001 & 0.109 & 0.582 \\
\hline
\end{tabular}

\section{Discussion}

According to our study, AMW has comparative advantage to be effective community health workforce, as they live in the hard-to-reach villages, speak the same dialect as the locals, understand the socio-cultural dimensions, and are well accepted by the community. This was also confirmed by a UNICEF study:

\section{....because of easy access, close social relationships, personal trust and social convenience, use of $A M W$ was very high especially in remote villages with limited geographical accessibilities. The same was true for $A M W$ residing in villages far from other health care facilities. Moreover, AMW were utilized in villages as a substitute for Traditional Birth Attendants, who became defunct due to senility or disabilities [22].}

Auxiliary health workforce or community health volunteers though seen as a good strategy to fill the human resource gaps, particularly in the remote and rural areas, difficulty to retain and maximize the contributions by these community health volunteers is a challenge faced by many countries [23]. Exploring for solution, studies indicated work environment [24], altruism, social recognition, knowledge gain and career development as different motivation factors for lay health workers (LHW) [25]. Similarly, altruism was the main motivation to be an AMW in Myanmar. Further, financial incentive, medical supplies, and timely replenishment of AMW kits with adequate supervision, are critically needed to retain and improve the productivity of AMWs.

Sustainable and standardised financial incentive is needed not only to motivate the AMWs, but also to avoid financial burden on the rural community. For instance, AMWs make substantial investment for their travel costs when visiting people's homes, time costs when they must get time-off from their routine productive work, and for the purchase of medicines and other basic medical supplies. Unavoidably, these costs are shouldered either by the community or the patients. Naturally in Myanmar, $39 \%$ of AMWs received financial support from the patients they served and $9 \%$ from the community, which can create financial burden on the rural community.

AMW kits are critical tools, necessary in performing their core functions of ensuring sanitary and safe conditions for woman in labour, during delivery and postnatal care. The kits contain a plastic sheet, a bar of soap, a two-sided clean razor blade, cord ties, and pictorial instructions on how to deliver a child. All these are consumables and need a system of regular replenishment to avoid service disruption.

While recognising the value of community health volunteers, evidence to prove their contribution is essential to sustain policy support [17]. Findings from our study 
indicated their meaningful contribution in delivering $\mathrm{MCH}$ services. It showed, in the last six months prior to the study, AMW assisted an average of nine deliveries, eleven antenatal care cases and nine postnatal cases, which was similar to UNICEF study-an average 10.3 assisted delivery [22]. AMW's contribution in delivering $\mathrm{MCH}$ services is further confirmed through another study in Kyimyindaing Township in Myanmar. According to that particular study, urban women in Kyimyindaing Township received ANC mainly from specialist and medical doctors (68.7\%); yet majority of rural women consulted AMWs (84 \%) for ANC services [26]. Hence, essential it is to enhance the support system to strengthen and sustain their contribution.

Assessing the determinants of attrition of auxiliary health workers is critical for their retention, as not many studies focused on this [27]. Responding to such need, our study explored the relationship between age, education and recruitment pattern of AMW, and their willingness to continue service. In Myanmar, age group and recruitment pattern of AMWs play a key role in their attrition. The older the AMW, the higher is the probability of their intention to serve more than five years.

Further, AMWs who volunteered their application, and those who applied prior to year 2000 had higher confidence to serve more than 5 years. Such findings clearly indicate the need for policy intervention and system support to provide regular refresher courses for the older and senior volunteers, to ensure service quality. On the other hand, it also questions the scaling up potential and sustainability of AMW program in the longer run, as the newer batch of AMWs are less keen to continue service. Hence, comprehensive streamlining of AMW program in Myanmar is worthwhile, to attract more new volunteers to sign up, and motivate all existing ones to continue, and provide quality services.

Responding to shortage of health workforce, WHO recommends to train and empower "mid-level' and 'lay' health workers to perform specific interventions that may else be performed by specialized cadre of health workers, to improve access to care [28]. Consequently, task shifting defined as the process of delegation, where tasks are moved to less specialized health workers [29], was commonly practiced in several countries facing critical shortage of health workforce, notably in South Asian and Sub-Saharan African countries.

Training and deployment of AMW is clearly supporting this recommendation by shifting some of midwives task to them especially in hard-to-reach areas. A successful task shifting requires a comprehensive national policy and guidelines where legal protection is in place for those undertaking additional tasks, clear policies toward supporting them to provide quality service, under close supervision and support.
Despite the merits of task shifting as an important policy option to improve workforce shortages; there are several concerns, for example, task shifting in HIV/AIDS in sub-Saharan Africa noted quality and safety concerns [30], professional and institutional resistance, and the need to sustain motivation and performance [31].

The limitation of this study is lack of assessment of the quality of services provided by the AMWs. Further, due to time and data limitation, it could not assess the proportion of contributions made by AMWs, as compared to other categories of health workers, particularly the midwives. Besides, the questionnaire is self-reported and this made it difficult to control the quality and honesty of reporting.

\section{Conclusion}

Comprehensive policy interventions and adequate support systems are critical to sustain and strengthen the contributions of AMWs in sharing the workload of BHS. Health volunteers, such as AMWs are recognised as extremely important in supporting the achievement of Health related MDGs and SDGs in many low-income countries [32,33].

In addition to strengthening the AMWs, Myanmar must adopt the long-term solution of training more midwives and retain them in rural hard to reach areas, as recommended by WHO [34], such as recruitment of young rural women for midwifery training, strengthen midwifery training institutes. Also intensify policy interventions to ensure a high level of retention in rural areas, through hometown work placements upon graduation, financial and non-financial incentives; provision of adequate medicines and supplies, support and supervision by township peers, and daily travel allowances.

\section{Additional file}

\section{Additional file 1: Questionnaire. (PDF $125 \mathrm{~kb}$ )}

\section{Acknowledgement}

The authors wish to thank the Ministry of Health, the Republic of the Union of Myanmar, and WHO Country Office Myanmar, for organising the internal peer review of this article. We thank all the basic health workers and health system strengthening officers, of sample townships in Myanmar for their kind contribution and support.

\section{Funding}

GAVI Health System Strengthening support to Myanmar.

\section{Availability of data and materials}

The questionnaire used in the study is shared as "the Additional file 1 Questionnaire". The data supporting the conclusions of this article contains the location and individual personal data, which must be kept confidentially.

\section{Authors' contribution}

SW, VT and WP contributed significantly in the study design. SW and VT did literature review and prepared the first draft; RS, WMMH, TTA, CK, WP, PTH reviewed and provided inputs to the draft; SW, WMMH, TTA and PTH involved in data collection; RS, VT, CK and WP did data analysis. All authors read and agreed upon manuscript. 


\section{Competing interests}

The authors declare that they have no competing interests.

\section{Consent for publication}

"Not applicable".

\section{Ethics approval and consent to participate}

The study was conducted as a part of routine program monitoring. Hence, the Ministry of Heath, the Republic of the Union of Myanmar waived the ethical clearance. Informed consents were sought and protection of confidentiality was strictly followed.

\section{Author details}

${ }^{1}$ International Health Policy Program (IHPP), Ministry of Public Health, Tiwanon Road, Nonthaburi 11000, Thailand. ${ }^{2} \mathrm{MoH}$, Myanmar, Naypyitaw, Myanmar. ${ }^{3}$ Independent consultant, Naypyitaw, Myanmar.

Received: 22 March 2016 Accepted: 24 August 2016

Published online: 01 September 2016

\section{References}

1. World Bank. Gross National Income, per capita, Atlas methos and PPP. 2015. http://databank.worldbank.org/data/download/GNIPC.pdf. Accessed 29 Aug 2016.

2. The World Bank. TAC Economics: Monitoring Progress Towards the Millennium Development Goals. http://www.mdgtrack.org/index. php?tab=c\&c=MMR\&g=6\#goals. Accessed 12 Feb 2015.

3. World Health Organisation. Global Health Expenditure Database. 2016. http://apps.who.int/nha/database/ViewData/indicators/en. Accessed 29 Aug 2016.

4. Victoria CG, Wagstaff A, Armstrong-Schellenberg J, Gwatkin D, Claeson M. Applying an equity lens to child health and mortality: more of the same is not enough. Lancet. 2003;362:233-41.

5. Christopher JB, Le May A, Lewin S, Ross DA. Thirty years after Alma-Ata: a systematic review of the impact of community health workers delivering curative interventions against malaria, pneumonia and diarrhoea on child mortality and morbidity in sub-Saharan Africa. Hum Res Hth. 2011:9:27.

6. Global strategy on human resources for health: Workforce 2030. http:// www.who.int/hrh/resources/pub_globstrathrh-2030/en/. Accessed 29 Aug 2016

7. World Health Organization. Strengthening human resource for health in South-East Asia: time for action and commitment. SEARO: WHO: 2015.

8. Buchan J, Couper ID, Tangcharoensathien V, Thepannya K, Jaskiewicz W, Perfilieva G, Dolea C. Early implementation of WHO recommendations for the retention of health workers in remote and rural areas. Bull World Health Organ. 2013:91(11):834-40.

9. Chen L, Evans T, Anand S, Boufford Jl, Brown H, Chowdhury M, Fee E. Human resources for health: overcoming the crisis. Lancet. 2004;364(9449):1984-90.

10. World Health Organisation. The World Health Statistics 2014. Geneva: WHO; 2014.

11. World Health Organisation. The World Health Report 2006:Working together for health. Geneva: WHO; 2006

12. Saw YM, Win KL, Shiao LW, Thandar MM, Amiya RM, Shibanuma A, Jimba M. Taking stock of Myanmar's progress toward the health-related millennium development goals: current roadblocks, paths ahead. Int J Equity Health. 2013;12:78.

13. Department of Population and UNFPA. Country Report on 2001 Fertility and Reproductive Health Survey. Nay Pyi Taw: Department of Population Ministry of Immigration and Population and UNFPA Myanmar; 2001.

14. Department of Population and UNFPA. Country Report on 2007 Fertility and Reproductive Health Survey. Nay Pyi Taw: Department of Population, Ministry of Immigration and Population and UNFPA Myanmar; 2007.

15. Ministry of Health Myanmar. Health Workforce Strategic Plan 2012-2017. http:// www.nationalplanningcycles.org/sites/default/files/country_docs/Myanmar/ health_workforce_strategic_plan_2012-2017.pdf. Accessed 13 Mar 2016.

16. Campbell J, Admasu K, Soucat A, Tlou S. Maximizing the impact of community-based practitioners in the quest for universal health coverage. Bull World Health Organ. 2015;93(9):590-590A

17. Gilmore B, McAuliffe E. Effectiveness of community health workers delivering preventive interventions for maternal and child health in low-and middle-income countries: a systematic review. BMC Public Health. 2013;13(1):847.
18. Callaghan M, Ford N, Schneider H. Review a systematic review of task-shifting for HIV treatment and care in africa. Hum Resour Health. 2010;8(8):16.

19. Hongoro C, McPake B. How to bridge the gap in human resources for health. Lancet. 2004;364(9443):1451-6.

20. Truth AU. No Health without a workforce. World Health Organisation (WHO) Report. 2013.

21. http://www.ncbi.nlm.nih.gov/pubmed/866563. Accessed 4 June 2016.

22. UNICEF. Myanmar. Assessment of Performance and Acceptability of Auxiliary Midwives in Rural Communities as a Strategy to Improve Maternal Health, 2004-2005. 2005. http://www.unicef.org/myanmar/Assessment_of_AMW_ in Rural.pdf. Accessed 15 Feb 2015.

23. Bhutta ZA, Ali S, Cousens S, Ali TM, Haider BA, Rizvi A, Black RE. Alma-Ata: rebirth and revision 6 interventions to address maternal, newborn, and child survival: what difference can integrated primary health care strategies make? Lancet. 2008;372(9642):972-89.

24. Jaskiewicz W, Tulenko K. Increasing community health worker productivity and effectiveness: a review of the influence of the work environment. Hum Resour Health. 2012;10(1):38.

25. Glenton C, Colvin CJ, Carlsen B, Swartz A, Lewin S, Noyes J, Rashidian A. Barriers and facilitators to the implementation of lay health worker programmes to improve access to maternal and child health: qualitative evidence synthesis. The Cochrane Library. 2013.

26. Sein KK. Maternal health care utilization among ever married youths in Kyimyindaing Township, Myanmar. Matern Child Health J. 2012;16(5):1021-30.

27. Nkonki L, Cliff J, Sanders D. Lay health worker attrition: important but often ignored. Bull World Health Organ. 2011:89(12):919-23.

28. World Health Organisation. WHO recommendations 2012: Optimizing health worker roles to improve access to key maternal and newborn health interventions through task shifting. Geneva: WHO; 2012.

29. WHO/PEPFAR/UNAIDS. Task shifting : rational redistribution of tasks among health workforce teams : global recommendations and guidelines. Geneva: WHO; 2008. http://www.who.int/healthsystems/TTR-TaskShifting.pdf. Accessed 15 Feb 2015

30. Zachariah R, Ford N, Phillips M, Lynch S, Massaquoi M, Janssens V, Harries AD. Task shifting in HIV/AIDS: opportunities, challenges and proposed actions for sub-Saharan Africa. Trans R Soc Trop Med Hyg. 2009;103:549-58.

31. Fulton B, Scheffler R, Sparkes S, Auh E, Vujicic M, Soucat A. Health workforce skill mix and task shifting in low income countries: a review of recentevidence. Hum Resour Health. 2011;9:1. http://www.human-resourceshealth.com/content/9/1/1. Accessed 15 Feb 2015.

32. Singh P, Sachs JD. 1 million community health workers in sub-Saharan Africa by 2015. Lancet. 2013;382(9 889):363-5.

33. World Health Organisation. SIXTY-NINTH WORLD HEALTH ASSEMBLY : A69/B/CONF./4 Agenda item 16.1. Geneva: WHO; 2016. http://apps. who.int/gb/ebwha/pdf files/WHA69/A69_BCONF4-en.pdf. Accessed 9 June 2016

34. World Health Organization. Increasing access to health workers in remote and rural areas through improved retention: Global policy recommendations. Geneva: WHO; 2010. http://www.who.int/hrh/retention/ guidelines/en/. Accessed 20 Jan 2014

\section{Submit your next manuscript to BioMed Central and we will help you at every step:}

- We accept pre-submission inquiries

- Our selector tool helps you to find the most relevant journal

- We provide round the clock customer support

- Convenient online submission

- Thorough peer review

- Inclusion in PubMed and all major indexing services

- Maximum visibility for your research

Submit your manuscript at www.biomedcentral.com/submit
) Biomed Central 